\title{
Sensory evaluation of wheat-cassava-soybean composite flour (WCS) bread by the mixture experiment design
}

\author{
Udofia P. G. ${ }^{*}$, Udoudo P. J. and Eyen N. O. \\ Department of Hotel and Catering Management, Akwa Ibom State Polytechnic, Ikot Osurua, Akwa Ibom State, Nigeria.
}

Accepted 26 August, 2013

\begin{abstract}
Wheat flour is unique for bread baking, but due to high cost of wheat, its continuous use in a developing economy is no longer encouraged. Cassava is a high carbohydrate bearing crop while soybean has a good history of health-giving nutrients. Both plants are indigenous to the tropics, they are cheap and available, but are grossly underutilized in the bread industry. To study sensory effect of supplementation of non-wheat flour in bread, the Simplex-Centroid Design of the mixture experimental design $\{3,3\}$ of the response surface methodology (RSM) was adopted. Fifteen (15) samples of bread samples were baked with each blend of the WCS composite flour. The bread samples were subjected to sensory evaluation by a panel of semi-trained panelists who had eaten bread for a long time. Optimization analysis on the data obtained from the sensory session showed that blend of 0.67:0.17:0.17 of wheat, cassava and soybean composite flour, respectively produced the best composite bread followed by pure blends of wheat bread in terms of taste, colour, texture, aroma, acceptability and preference. More work should be advanced on other factors of using composite flour for bread manufacturing as well as the promotion of the products on account of health claims of the product.
\end{abstract}

Key word: Sensory evaluation, composite flour, mixture experimental design, simplex-centroid design, response surface methodology (RSM), optimization.

\section{INTRODUCTION}

Most Nigerians are consuming bread as a traditional food item. Wheat flour is the major component of bread. Since wheat is not a tropical crop, it is imported at high cost to meet the rising trend in demand. According to David (2006), Nigeria is the world's largest importer of American red winter wheat. The rising trend of wheat importation may continue due to the relatively stable exchange rate, competitive prices of wheat, high crude oil prices and modest economic growth, besides, close substitute of wheat is yet to be identified among carbohydrate bearing crop (David, 2006). Efforts of governments to embark on local production of wheat have been failing; the situation is not likely to improve on account of unfavorable agronomic conditions of the crop in Nigeria.

The presence of glutein and glutenin confers wheat with unique baking properties. Wheat also contains other nutrients though in marginal amounts which may not support good health all on its own. Wheat may contain some anti -nutritional factors like phytate and tannins especially if not properly processed (Jayacopal, 2012).

Cassava is a tropical crop with high content of carbohydrate; most cassava varieties exhibit high level of 
Table 1. Experimental layout of the Simplex Centroid Design showing un-randomized runs.

\begin{tabular}{lccc}
\hline Run & A & B & C \\
\hline 1 & 0.33 & 0.33 & 0.33 \\
2 & 0.00 & 0.50 & 0.50 \\
3 & 0.00 & 0.00 & 1.00 \\
4 & 0.17 & 0.17 & 0.67 \\
5 & 1.00 & 0.00 & 0.00 \\
6 & 0.50 & 0.50 & 0.00 \\
7 & 0.00 & 1.00 & 0.00 \\
8 & 0.00 & 0.00 & 1.00 \\
9 & 0.00 & 1.00 & 0.00 \\
10 & 1.00 & 0.00 & 0.00 \\
11 & 0.50 & 0.50 & 0.00 \\
12 & 0.17 & 0.67 & 0.17 \\
13 & 0.50 & 0.00 & 0.50 \\
14 & 0.67 & 0.17 & 0.17 \\
\hline
\end{tabular}

Run = product from the respective mixture; $A=$ Wheat flour, $B=$ cassava flour, $C=$ soybeans flour.

tolerance for poor agronomic conditions. Though some cassava varieties contain cyanide, however genetic engineering and improved processing methods are alleviating cyanide toxicity problems. Cassava does not contain the two proteins which makes wheat a preferred major baking ingredient. Physiochemical properties of cassava starch are suitable for supplementation of wheat flour in bread-making without compromising its sensory attributes (Eduardo et al., 2013).

Soybean is another major crop of the tropics, apart from its ability to strive in the tropical climate; it is a health plant due to good content of protein and other phytochemicals (Aleke et al., 2000). The FDA says that $25 \mathrm{~g}$ of soy protein per day can reduce the risk of coronary heart disease. The UK Joint Health Claims Initiative $(\mathrm{JHCl})$ re-confirmed the assertion with a similar claim in 2002.

Sensory evaluation evokes, measures, analyses and interprets responses to products as perceived by senses of sight, smell, touch, taste and hearing (Stone and Sidel, 1993). The consumer buys nutrition, convenience, image and functionality in food. Therefore, new products must provide all the responses like or near the older product.

This study was devoted to the determination of sensory properties, preference of bread samples baked with blends of different proportions of wheat, cassava and soy bean flours. The sensory session used a taste panel of staff and students of the Department of Science Technology, Akwa Ibom State Polytechnic, Ikot Ekpene, Nigeria using the mixture experimental design of the response surface methodology (RSM).

\section{MATERIALS AND METHODS}

One hundred percent (100\%) American hard red winter wheat flour was obtained from Niger Mills, Calabar. TMS (4) 1425 cassava variety was obtained from the International Institute of Tropical Agriculture (IITA) through the Root Crop Research Institute, Umudike. Other baking ingredients: yeast, fat, baking powder, sugar and salt, were obtained from a baking shop, all in lkot Ekpene, Nigeria.

\section{Preparation of cassava flour}

The cassava tuber was peeled about 10 hours post-harvest, washed, sliced thinly with a papaya shredder (Qlink, China), removing the fibre part. The shredded cassava was washed with ample of clean water and allowed to drain, it was thinly spread on a straw mat spread on a clean concrete surface and sun dried for about $11 \mathrm{~h}$ until it was water drip-free before it was transferred to an hot air oven (Therma Grosskuchen, Le Chef, Sweden) at about $60^{\circ} \mathrm{C}$ until the moisture content was reduced to about $13 \%$ dry basis.

The cassava flake was ground through a corn meal grinder to pass through a sieve DIN $4188(0.12 \mathrm{~mm})$ aperture. The cassava flour was packed in plastic buckets.

\section{Preparation of soy bean flour}

Soy bean flour was screened of foreign bodies, washed with ample of clean water, soaked in boiling water for $24 \mathrm{~h}$. Seed coat was removed from the soaked seed and sun dried for $12 \mathrm{~h}$ to reduce water content to about $13 \%$. It was then fried to brittleness before ground with a Waring blender (Model 5011, Waring Products Corp. New Hartford, CT, USA) into powder and sieved through DIN $4188(0.12 \mathrm{~mm})$ aperture sifter and stored for experiments.

\section{Experimental design}

Blends (mixtures) are combinations of components that together produce an end product having one or more properties of interest (Cornell and Piepel, 2008). Response in mixture experiment is a function of proportions and not amounts of the mixture components. Given these two conditions and fixing the total (an equality constraint) facilitates modeling of the response as a function of component proportions (Huguo, 2002).

Mixture experimental design assumes Equation 1,

$Y_{i}=\beta_{1} x_{1}+\beta_{2} x_{2}+\beta_{3} x_{3}+\beta_{12} x_{1} x_{2}+\beta_{13} x_{1} x_{3}+\beta_{23} x_{2} x_{3}+\beta_{i j} x_{i j}^{2} \ldots 1$

where $Y_{i}$ is the response, the $\beta$ symbols represent coefficient to be fitted via regression analysis, $x_{1}, x_{1} x_{2}$, xij ${ }^{2}$ are the linear, interaction and quadratic effect of the components respectively.

A simplex-centroid design consists of all points that are equally weighted mixtures of 1 to q components. The components are distributed as presented in Table 1. The small option of the design was used in the allocation of the mixture components resulting in 14 bread samples (Table 1).

\section{Preparation of composite flour}

Composite flour was prepared by intimate mixture of proportions of the three component flours according to Table 1 (Huguo, 2002). Blends of the mixture were the pure $(A, B, C)$, binary $A B, A C, B C)$ and overall centroid $(A B C)$. 
Table 2. Experimental layout and responses.

\begin{tabular}{lccccccccc}
\hline Run & A & B & C & Taste & Colour & Aroma & Texture & Pref. & Accpt. \\
\hline 1 & 0.33 & 0.33 & 0.33 & 3.00 & 7.00 & 8.00 & 2.00 & 2.00 & 2.00 \\
2 & 0.00 & 0.50 & 0.50 & 7.30 & 4.00 & 7.00 & 2.00 & 3.00 & 4.00 \\
3 & 0.00 & 0.00 & 1.00 & 2.00 & 2.00 & 7.00 & 2.00 & 3.00 & 2.00 \\
4 & 0.17 & 0.17 & 0.67 & 3.00 & 6.00 & 6.00 & 4.00 & 5.00 & 6.00 \\
5 & 1.00 & 0.00 & 0.00 & 9.00 & 8.50 & 5.00 & 9.00 & 9.0 & 8.00 \\
6 & 0.50 & 0.50 & 0.00 & 6.00 & 7.80 & 8.00 & 6.00 & 7.00 & 8.00 \\
7 & 0.00 & 1.00 & 0.00 & 5.00 & 6.00 & 3.00 & 3.00 & 2.00 & 2.00 \\
8 & 0.00 & 0.00 & 1.00 & 2.30 & 3.00 & 2.00 & 2.00 & 3.00 & 2.00 \\
9 & 0.00 & 1.00 & 0.00 & 2.00 & 5.00 & 3.00 & 2.00 & 2.00 & 4.00 \\
10 & 1.00 & 0.00 & 0.00 & 8.60 & 9.00 & 6.00 & 8.50 & 9.00 & 8.00 \\
11 & 0.50 & 0.50 & 0.00 & 6.00 & 7.00 & 7.00 & 6.00 & 7.00 & 8.00 \\
12 & 0.17 & 0.67 & 0.17 & 5.00 & 8.00 & 6.00 & 6.00 & 6.00 & 5.00 \\
13 & 0.50 & 0.00 & 0.50 & 6.00 & 5.00 & 7.00 & 5.00 & 7.00 & 6.00 \\
14 & 0.67 & 0.17 & 0.17 & 8.00 & 9.00 & 8.00 & 8.00 & 9.00 & 8.00 \\
\hline
\end{tabular}

$\mathrm{A}$, wheat flour, $\mathrm{B}=$ Cassava flour, $\mathrm{C}=$ soybean flour, run $=$ experimental run, pref. $=$ preference, accpt. $=$ acceptability.

Table 3. $p$-Values of model, $R^{2}$ regression analysis of the models and mean score of hedonic tests.

\begin{tabular}{lcccccc}
\hline Analysis & Taste & Colour & Aroma & Texture & Accept. & Prefer. \\
\hline Model & 0.0002 & 0.0225 & 0.0452 & 0.0018 & 0.0286 & NS \\
Linear & 0.0012 & 0.0057 & NS & 0.0002 & 0.0059 & 00014 \\
AB & NS & NS & 0.0217 & NS & NS & NS \\
AC & NS & NS & NS & NS & NS & NS \\
BC & NS & NS & NS & NS & NS & NS \\
ABC & 0.0331 & S & S & S & S & S \\
& & & & & & \\
R $^{2}$ & 0.9254 & 0.7577 & 0.7069 & 0.8759 & 0.7411 & 0.8095 \\
Mean & 6.24 & 5.23 & 5.93 & 4.74 & 5.21 & 5.29 \\
\hline
\end{tabular}

$\mathrm{S}=$ significant, $\mathrm{NS}=$ not significant.

\section{Preparation of dough and baking}

The composite flour dough was prepared and baked according to the method specified by Eddy et al., (2007) and Edwardo et al. (2013).

All the ingredient; yeast $3 \mathrm{~g}$, salt $4 \mathrm{~g}$ sugar $5 \mathrm{~g}$, margarine $9 \mathrm{~g}$, water, according to the absorption capacity of blend were initially mixed in a mixing machine, (KitchenAid, USA). Different levels of water were mixed for $2.5 \mathrm{~min}$ at the low machine speed and for 8 min at the medium machine speed with the original dry mix of each blend until soft dough resulted. After the first fermentation, the dough was divided into $40 \mathrm{~g}$ portions rounded, and placed into bread baking pans and proofed for another 40 min in an improvised fermentation cabin at about $35^{\circ} \mathrm{C}$ and $80 \%$ relative humidity. The proofed dough of blends were baked in a hot air oven (Therma Grosskuchen, Le Chef, Sweden) at $210^{\circ} \mathrm{C}$ for $8 \mathrm{~min}$. The bread samples were allowed to attain room temperature $\left(28.0 \pm 1.0^{\circ} \mathrm{C}\right)$ before used for sensory evaluation.

\section{Sensory evaluation}

Samples of the composite bread were served to a 10 member semi- trained panelists who were familiar with the major sensory attributes of good quality bread: taste, aroma, texture, colour of the samples. A 9-point hedonic scale of 9 (like extremely) to 1 (dislike extremely), was designed to measure the degree of preference of the samples. The samples were presented in identical containers, coded with 3digit random numbers and served simultaneously. The categorical scores of the sample parameters were converted to numerical scores ranging from 1 to 9 , with 1 as the highest and 9 as the lowest level of the quality attribute (Iwe, 2002).

\section{RESULTS}

Table 2 shows the experimental runs and the respective responses, Tables 3 and 4 show values of $2^{\text {nd }}$ polynomial fit, analysis of variance (ANOVA) and coefficient of estimates respectively for the data obtained from sensory evaluation.

Equations 2 to 7 are models (mathematical equations) of the parameters of composite bread samples which resulted from the experimental runs. The graphical 
Table 4. Coefficients of estimates.

\begin{tabular}{lccccccc}
\hline Parameter & A & B & C & AB & AC & BC & ABC \\
\hline Taste & 8.7859 & 5.5940 & 2.5601 & 1.3606 & -1.9268 & 0.9303 & 66.2963 \\
Colour & 9.1669 & 3.6288 & 2.0757 & -3.6774 & -3.0859 & 11.2856 & NS \\
Aroma & 5.6174 & 2.9507 & 4.4042 & 12.7761 & 7.4093 & 11.4093 & NS \\
Texture & 8.8823 & 2.7274 & 1.9964 & 2.3025 & -0.6808 & 0.7478 & NS \\
Accept. & 9.1968 & 2.2920 & 3.1042 & 4.7989 & 1.4418 & 0.0132 & NS \\
Prefer. & 8.1665 & 3.0713 & 2.3833 & 7.3115 & 0.9710 & 2.3995 & NS \\
\hline
\end{tabular}

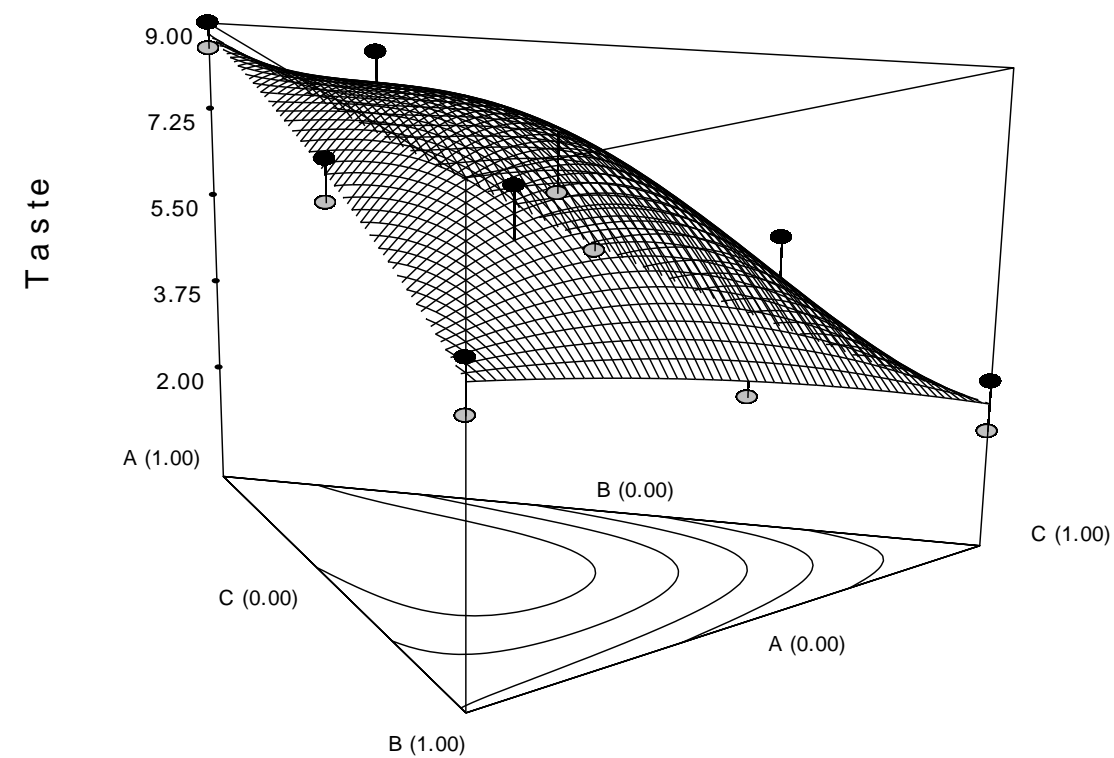

Figure 1. Response surface plot of bread on taste of bread samples; Taste $=8.78 \mathrm{~A}+$ $5.59 B+2.56 C+1.36 A B-1.92 A C+0.93 B C+66.29 A B C$ 1

presentation (Figures 1 to 4 ) plots visualize the fitted models in triangular surface plots.

\section{DISCUSSION}

\section{Taste}

Taste is an important sensory attribute of any food. Intake of bread is often enhanced by taste ( $\mathrm{Sim}$ and Tam, 2001). Table 2 shows a reduction in hedonic score of samples of bread with high proportions of cassava and soy bean flour. Table 2 also shows that bread samples from pure blend and blend of 0.67:0.17:0.17 wheat, cassava and soy bean composite flour, respectively, showed high sensory scores on taste. However, some panelists still expressed liking for the 'bad' samples. This observation may be attributed to personal choice or an influence of the experimental conditions. Soy bean flour has beany flavor and poor aroma (Janet and Nyla, 2001;
Dendy, 2013), addition of high proportions of the flour in the composite flour may introduce objectionable characteristics which overwhelmed the traditional taste attribute of the pure wheat flour blend samples and affected the choice of their taste. Table 3 shows that the taste model was significant $(p<0.05)$ and reliable, $\left(R^{2}=\right.$ 0.9245 ) with a mean hedonic score of 6.24.

Model of taste (Equation 1) shows that pure blend of the components was significant $(p<0.05)$, their cross products were not significant $(p>0.05)$ (bold type in Equation 1). Overall centroid of the components of mixture was significant $(p<0.05)$. The response surface plot (Figure 2) eluciates this observation.

\section{Colour}

Colour of bread crust is an important sensory attribute, which can enhance acceptability. The local population thinks that pale coloured bread crust is indicative of 


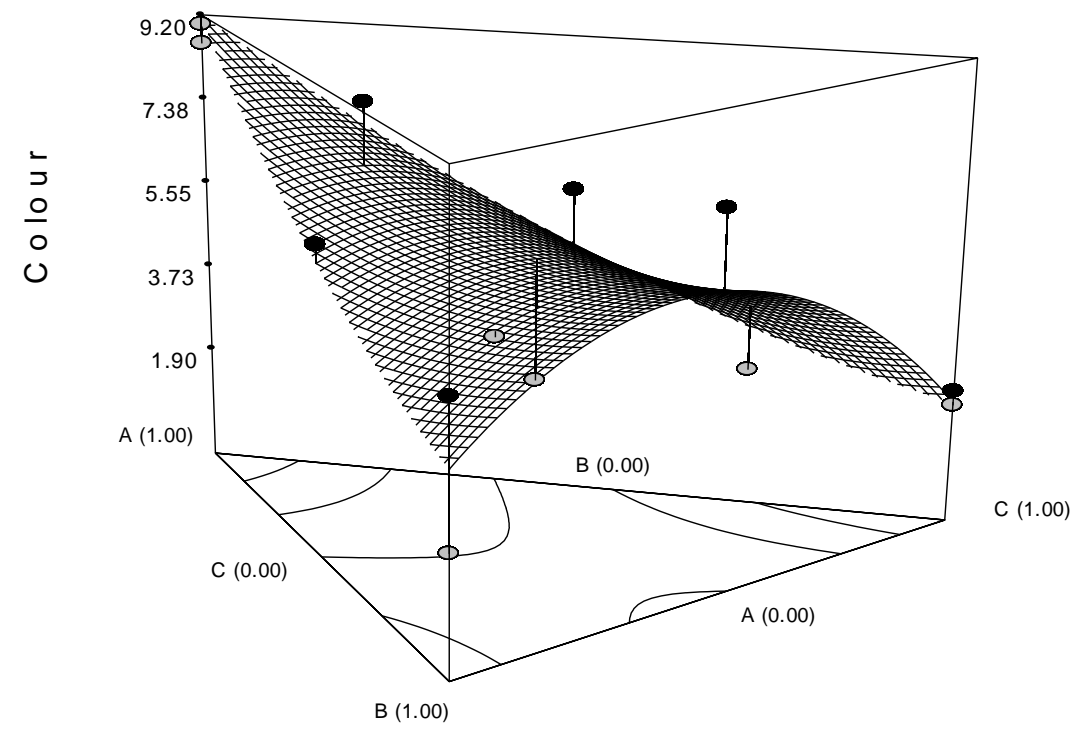

Figure 2. Response surface plot of bread on colour of bread samples; Colour = $9.17 A+3.63 B+2.08 C-3.08 A B-3.09 A C+11.29 B C$

(2)

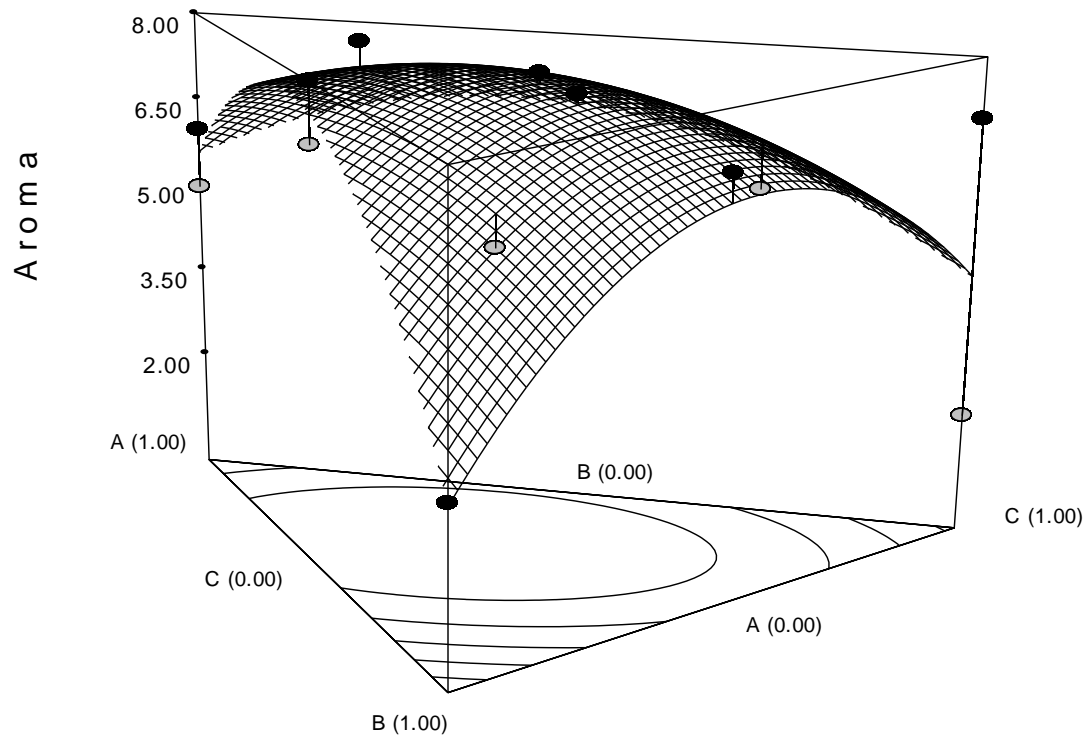

Figure 3. Response surface plot of bread on aroma of bread sample; Aroma = $5.61 \mathrm{~A}+2.95 \mathrm{~B}+4.40 \mathrm{C}+12.77+615 \mathrm{AB}+7.41 \mathrm{AC}+11.41 \mathrm{BC}+1.22 \mathrm{ABC}$.

improper baking. Besides it is assumed that the brown colour is what imparts nutrients, especially iron on the product. Browning of bread crust is an origin of Millard reactions during baking in the presence of amino acids, reducing sugars, temperature, time of baking and moisture levels of the fermented dough (Deny, 2013). Table 2 shows that browning was highest in samples with high supplementation of soy bean and cassava flours. This observation may be attributed to the high content of amino acids in soy bean and high content of sugars in cassava flours. However, all other blend samples showed some levels of brownness. Table 3 indicates that the models of the parameter was significant, $(p<0.05)$, showing an adequate quadratic fit $\left(\mathrm{R}^{2}=75.77 \%\right)$ and an overall mean hedonic score of 5.23.

Model 1 shows that all pure blends were significant, their cross products: $A B, A C$ and $B C$ were not significant, $p<0.05$, while their overall centroid was significant, 


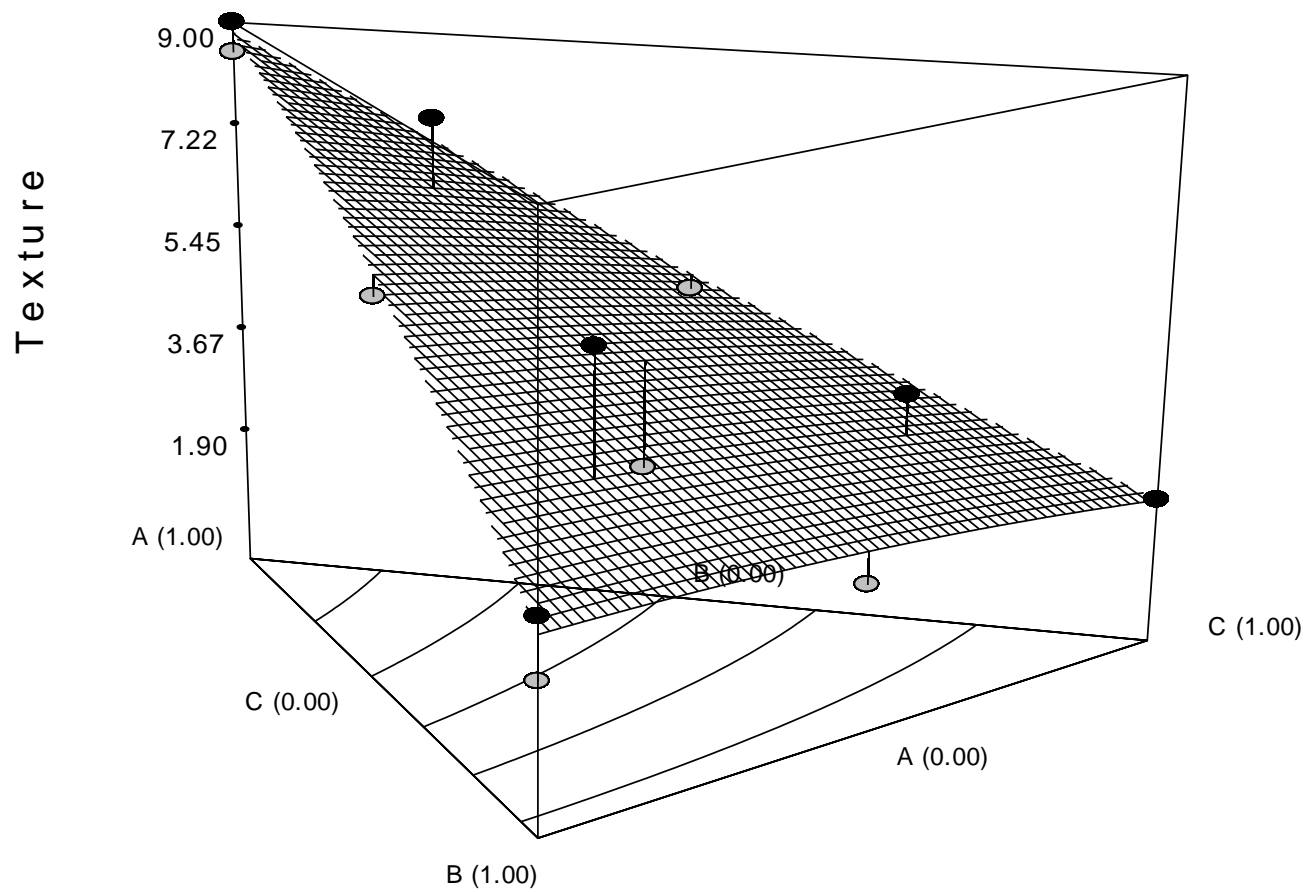

Figure 4. Response surface plot of bread on texture of bread samples; Texture $=8.824 \mathrm{~A}+2.72 \mathrm{~B}+$ $1.99 \mathrm{C}+2.30 \mathrm{AB}-\mathbf{0 . 6 8 A C}+0.75 B C$

$p<0.05$. The negative coefficient of estimate of crossproduct of AC suggested that pure components may produce higher coloured product than in combination. This observation was supported by Figure 1. Statistically, the model should exclude the non significant estimates of coefficient, but in practice the non-significant estimates are experimented for any slight positive effect they might introduce.

\section{Aroma}

Aroma is an important parameter of food (Iwe, 2002). 'Good' aroma from food excites the taste buds, making the system ready to accept the product. 'Poor' aroma may cause outright rejection of food before they are tasted. The model of aroma was not very significant $(p=$ 0.0452 ), while showing seemingly adequate quadratic fit $\left(R^{2}=70.69 \%\right)$.

The two cross-product terms in Table 4 (AC and BC) were not significant $(p>0.05)$ while the overall centroid were significant $(p<0.05)$, which was although included in the model, for further experiment-tation. The observation may be attributed to the beany aroma of raw soy bean, it may also be attributed to the strangeness of the product. Consumers attitudes may be tuned to accept new product if health claim, or social status is attached. In fact, there was the tendency for composite bread samples with high supplementation of wheat flour to consistency show high sensory scores.

\section{Texture}

Food texture sometime embraces appearance (Eduordo et al. 2013). Texture of composite bread samples were rated on a scale from 1 (heavy) to 9 (light). The mean texture scores of samples ranged from sample 8.5 for pure blends. Table 3 shows that samples of pure blends were significant $(p<0.05)$, the model showing adequate quadratic fit $\left(\mathrm{R}^{2}=87.59 \%\right)$ and a mean hedonic score of 4.74.

Terms in the model are coefficient of estimates (Table 4) and how they contribute to the parameter of the bread samples. Pure blend sample of $A, A B$ and $A B C$ were significant $(p<0.05)$. The observation indicates that high supplementation of non-wheat flour showed low scores on texture. High supplementation reduces elastic property of wheat flour dough rendering the dough incapable of retaining the gas emanating from fermentations (Giami et al., 2004).

\section{Optimization}

\section{Preference and acceptability}

Both acceptance and preference are primarily economic concept. Acceptance of food varies with standards of living and cultural background, whereas preference refers to selection when presented with choice (Huguo, 2002). Preference is often influenced by prejudices, religious 
principles, group conformance, 'status value' and snobbery, in addition to the quality of the food. People have preferences, no matter how illogical they may appear. Therefore, the parameters are difficult parame-ters to determine in a new product development ( $\mathrm{Sim}$ and Tam, 2001). In Table 2, hedonic scale scores for both parameters on the parameters showed a similar trend. The general trend is that the pure blend and low non-wheat composite flour samples showed strong likeness to colour, and texture also have strong positive influence on acceptability and preference. Models of both parameters are significant $(p<<0.005)$, predictable $\left(R^{2}=0.7411\right.$ and $\left.R^{2}=0.8095\right)$ respectively with mean scores of 5.21 and 5.29 .

Generally, optimization analysis showed that blend samples of $0.67: 0.17: 0.17$ of wheat flour, cassava and soybean flours respectively showed the highest hedonic scores after samples of pure blend of wheat flour.

\section{Conclusion}

In the study, it was observed that all samples of highly supplemented bread samples failed to meet the important parameters of pure bread; the failure hindered general acceptability and preference of the familiar bread sample. The high hedonic scores obtained in some of the new products was attributed to personal psychology of choice. However, samples of overall centroid blend showed encouraging scores on product acceptability. It is believed that regular supply, publicity and introduction of health claims on the products may enhance improved production strategy and quality. Besides, the product should be presented as the 'food for the rich'.

\section{REFERENCES}

Aleke DL, Germain AS et al. (2000). Isoflavone-rich soy protein isolate attenuates bone loss in the lumbar spine of perimenopausal women. Am. J. Clin. Nutr. 72(3):844-52.

David MO (2006). Nigeria, No. 1 market for U. S. wheat; potential for other grains and feeds, USAD Foreign Agricultural Service bulletin. pp. 1-2.

Dendy DAV (2013) Review of composite flour technology in the context of Tanzania. National Resources Institute, Chatham, UK. pp. 1-23.

Eddy NO, Udofia PG, Eyo D (2007). Sensory evaluation of wheat/cassava composite bread and effect of label information on acceptance and preference. Afr. J. Biotechnol. 6(16):123-134

Eduardo M, Svanberg U, Oliveira J, Ahrne L (2013). Effect of cassava flour characteristics on properties of cassava-wheat-maize composite bread types. Int. J. Food Sci. 1-10.

Giami GY, Amasisi T, Ekiyor G (2004). Comparison of bread making properties of composite flour from kernels of roasted and boiled African bread fruit (Treculia africana) seed. J. Mat. Res. 1 (1): 16-25.

Iwe MO (2002). Handbook of sensory methods and analysis. PROJOINT Communications Services Ltd, Enugu. pp. 70-72.

Sim J, Nya T (2001). Eating qualities of muffins prepared with $10 \%$ and $30 \%$ soy flour. J. Nutr. Recipe Menu Dev. 3:2.

Stone H, Sidel JL (1993). Sensory evaluation practices, Califonia: Academic Press. 